\title{
Colorectal cancer risk assessment and screening recommendation: a community survey of healthcare providers' practice from a patient perspective
}

Ryan J Courtney ${ }^{1,4^{*}}$, Christine L Paul ${ }^{4,3}$, Robert W Sanson-Fisher ${ }^{4}$, Finlay A Macrae ${ }^{2}$, Mariko L Carey ${ }^{4}$, John Attia ${ }^{4}$ and Mark McEvoy ${ }^{4}$

\begin{abstract}
Background: Family history is a common risk factor for colorectal cancer (CRC), yet it is often underused to guide risk assessment and the provision of risk-appropriate CRC screening recommendation. The aim of this study was to identify from a patient perspective health care providers' current practice relating to: (i) assessment of family history of CRC; (ii) notification of "increased risk" to patients at "moderately/potentially high" familial risk; and (iii) recommendation that patients undertake CRC screening.

Methods: 1592 persons aged 56-88 years randomly selected from the Hunter Community Study (HCS), New South Wales, Australia were mailed a questionnaire. 1117 participants (70\%) returned a questionnaire.

Results: Thirty eight percent of respondents reported ever being asked about their family history of CRC. Ever discussing family history of CRC with a health care provider was significantly more likely to occur for persons with a higher level of education, who had ever received screening advice and with a lower physical component summary score. Fifty one percent of persons at "moderately/potentially high risk" were notified of their "increased risk" of developing CRC. Thirty one percent of persons across each level of risk had ever received CRC screening advice from a health care provider. Screening advice provision was significantly more likely to occur for persons who had ever discussed their family history of CRC with a health care provider and who were at "moderately/ potentially high risk".
\end{abstract}

Conclusions: Effective interventions that integrate both the assessment and notification of familial risk of CRC to the wider population are needed. Systematic and cost-effective mechanisms that facilitate family history collection, risk assessment and provision of screening advice within the primary health care setting are required.

\section{Background}

Colorectal cancer (CRC) screening: reduces the burden of disease

Worldwide, CRC comprises $9.4 \%$ of all cancer cases with one million diagnoses annually [1]. Survival from CRC is highly stage-dependent yet fewer than $40 \%$ of CRCs are diagnosed at a localised stage [2]. Screening is a costeffective mechanism that reduces the incidence and

\footnotetext{
* Correspondence: ryan.courtney@newcastle.edu.au

${ }^{1}$ The Priority Research Centre for Health Behaviour, School of Medicine and Public Health, Faculty of Health, The University of Newcastle, Newcastle, Australia

Full list of author information is available at the end of the article
}

mortality associated with CRC [3-5]. Population-based screening is recommended for those aged 50 years or older, with average-risk persons recommended to receive periodical Faecal Occult Blood Test (FOBT) screening or endoscopy screening, dependent on screening guidelines [6,7]. Several randomised controlled trials (RCTs) have indicated it is possible to reduce mortality from CRC mortality by $15 \%$ to $33 \%$ with Faecal Occult Blood Test (FOBT) screening on either an annual or biennial basis[3,4,8-10]. Recent RCT evidence of onceonly flexible sigmoidoscopy for persons 55-64 years of age provides strong evidence for the substantial and

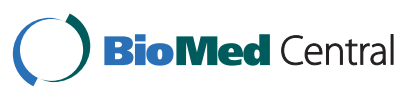


long-term benefit of this procedure [11]. This study indicated a one-third reduction of incidence and $40 \%$ reduction in mortality for persons undertaking sigmoidoscopy screening [11]. Although colonoscopy remains untested in randomised trials, case control and cohort studies using large-bowel endoscopy have shown a CRC mortality reduction rate ranging from $60 \%$ to $76 \%$ [12] and incidence reduction of $76 \%$ to $90 \%$ [5].

\section{Family history is a common and important risk factor}

Relatives of CRC patients are a group that can benefit from targeted screening or prevention programs [13]. Approximately $15 \%$ to $20 \%$ of CRC cases occur in persons who have a first degree relative with the disease [14-16]. Relative risk is up to two-fold for persons with a first-degree relative diagnosed with CRC and three- to six-fold for families with additional factors such as early onset of CRC or multiple relatives affected $[6,17]$. The presence of genetically-based familial syndromes, such as hereditary non-polyposis CRC (HNPCC) and familial adenomatous polyposis (FAP) further increases the risk of CRC in first-degree relatives $[7,14]$. Screening guidelines in Australia categorise asymptomatic individuals into three levels of risk: "at or slightly above average risk"; "moderately increased risk'; and "potentially high risk". Risk is quantified based on family history of CRC: number and type of relative diagnosed (first or second-degree relative) and their age at diagnosis, with additional high-risk features considered [6].

\section{CRC risk assessment in the primary care setting}

Health care providers play an integral role in cancer control by identifying those individuals whose behaviour, environment or family history place them at increased risk of CRC [18].

In Australia, CRC screening guidelines entrust healthcare providers with preventive practices relating to: patient family history of CRC assessment; the notification of persons at increased-risk; and the provision of risk-appropriate CRC screening advice [6]. However, evidence suggests that family-health histories are seldom taken in primary-care [19]. This may be due to the competing demands for care and time factors that are placed on general practitioners [20,21]. In addition, the complexity of familial-risk interpretation and the lack of systematic collection and assessments methods to assist primary-care providers further compound this problem [19]. Retrospective chart audits have demonstrated that $40 \%$ to $55 \%$ of patient medical records include important family history information (i.e. the presence or absence of breast or bowel cancer) [22,23]. Clinicians' self reported rate of patient family history assessment ranges from $30 \%$ to $90 \%[24,25]$. Direct observation studies suggest discussion of family history may occur in
$51 \%$ of visits by new patients and $22 \%$ of visits with established patients [26]. However, relatively little is known about current practice relating to health care providers' identification and notification of persons at elevated-risk of CRC. The few studies $[18,23,27,28]$ which have assessed this issue have been conducted within North American family practice settings adopting patient record audit.

\section{The opportunity often missed: CRC screening recommendation to patients}

Medical practitioner recommendation can increase the likelihood of complying with CRC screening up to 23times $[29,30]$, with over $75 \%$ of persons reporting that they would undertake screening if it were recommended by a doctor $[31,32]$. Nonetheless, CRC screening recommendations are neither routinely nor consistently provided to at-risk patients [33-36]. Population-based data from the United States National Health Interview Survey (NHIS) indicated that only $10 \%$ of under-screened patients who had visited their doctor in the previous year had received a CRC screening recommendation [35]. In Australia, a recent evaluation of at-risk persons (aged 30-70 years) presenting to an out-patient hospital setting identified that $22 \%$ of persons had ever received any CRC screening recommendation from their medical practitioner [37].

To our knowledge the current study presents as the first community-based evaluation of health care providers practice relating to CRC family history assessment and notification of "increased risk" to persons at elevated levels of familial risk ("moderately increased/ potentially high risk"). Further, the socio-demographic, lifestyle or psychosocial factors associated with family history assessment of CRC and provision of screening advice outside of the general practice setting is understudied [35]. Both the identification of these factors and sub-groups less likely to receive CRC family history assessment and screening advice is of importance for the development and improvement of future preventive programs in the general practice setting. The aim of this study was to examine among a community-based cohort of at-risk persons (aged 56-88 years), the proportion of respondents:

(i) Who had ever been asked by a health care provider about their family history of CRC

(ii) At elevated levels of familial risk ("moderately increased/potentially high risk") who had been notified by a health care provider of their "increased risk" of developing CRC.

(iii) Who had ever received CRC screening advice from a health care provider.

Socio-demographic, clinical and psychosocial characteristics associated with ever asked about family history 
of CRC and ever received CRC screening advice were identified.

\section{Methods \\ Design and study population}

The Hunter Community Study (HCS) sample is a longitudinal cohort of community dwelling men and women aged 55-85 years at baseline in the Hunter Region, NSW, Australia [38]. Participants were randomly selected from the NSW State electoral roll between December 2004 and 2007. The HCS cohort reflects the Hunter Region, state and national profiles for gender and marital status, but is slightly younger in age [38]. A randomly selected sub-sample of HCS participants ( $\mathrm{n}=$ 1592 ) aged 56-88 years at time of survey (November, 2009) were mailed a pen and paper questionnaire.

\section{Questionnaire}

Respondents were asked about health care providers' practice relating to assessment of family history of CRC - "Has any health professional e.g. your doctor, ever asked if you have a family history of bowel cancer" (Yes/ No), notification of "increased risk" of developing CRC "Did this person discuss whether there was a possible 'increased risk' of developing bowel cancer for you or your family members?" (Yes/No), and the provision of CRC screening information - "Has any health professional suggested that you or your relatives should do any of the following: Please choose all that apply." (i. Start having screening tests for bowel cancer/ii. Talk to their doctor about screening tests/iii. No advice has ever been given/iv. Take other action related to bowel cancer (please specify____. Responses to questions relating to ever asked about family history of CRC by a health care provider and notification of possible increased risk were used to derive a Discussion of family history of CRC with doctor variable with three levels (never discussed, discussed and informed of possible "increased risk", discussed and not informed of possible "increased risk"). Respondents' answers concerning provision of CRC screening information were used to derive an ever received screening advice from doctor variable (Yes/No). Respondents indicating (i), (ii), or (iv) were coded as ("Yes") to receiving screening advice while respondents answering (iii) were coded as ("No").

\section{Respondents familial risk based on self reported family history of CRC}

Respondents were asked separately whether any first- or second- degree relatives had ever been diagnosed with CRC and if so, their age at diagnosis. Survey items used to assess family history of CRC are presented in Additional file 1: Appendix A. Respondents' self reported family history of CRC was used to allocate persons to their level of risk in accordance with current clinical practice guidelines (see Table 1).

\section{Statistical Analysis}

Frequency distributions (n/\%) with 95\% confidence interval were used to assess the proportion of respondents that had ever been asked about their family history of CRC by a health care provider (Yes/No) and ever received CRC screening advice (Yes/No). For persons at elevated level of risk ("moderately increased/ potentially high risk") the proportion notified of their "increased risk" was identified. The following items selected from the HCS databank were assessed as potential correlates of ever asked about family history of CRC and ever received CRC screening advice: Socio-demographic and lifestyle, i.e. age, gender, education, marital status, country of birth, household income, retirement, private health insurance status, tobacco or alcohol use; Clinical, i.e. general practice visits per year, previous cancer diagnosis (excluding CRC), body mass index, and co-morbidity (e.g. high cholesterol, hypertension, asthma, diabetes); and psychosocial, i.e. physical health, assessed using the physical health component summary score (PCS) on the short form health survey SF-36 [39], and mental health assessed using the Kessler Psychological Distress Scale (K-10) [40]. The PCS is a physical health summary score aggregated from the physical functioning, role-physical, bodily pain and general-health scales on the SF-36 [41]. Multiple logistic regression analysis was used to determine independent factors associated with ever asked about family history of CRC by a health care provider and ever received CRC screening advice. Variables with a $p$ value $<.25$ following simple logistic regression analysis (See Additional file 1: Appendix B) were entered into multiple logistic regression model (with both forward and backward stepwise elimination used to check consistency of results). Variables that met the significance cut-point of ( $p$ value < $.05)$ were entered into the final model. Data were analysed using STATA 11 (STATA, Texas, USA).

\section{Ethics approval}

The University of Newcastle and Hunter New England Population Health Human Research Ethics Committees granted ethical approval.

\section{Results}

\section{Characteristics of the sample}

Of the 1592 mailed surveys, 1117 respondents completed and returned surveys (response rate, 70\%). Respondents previously diagnosed with CRC $(\mathrm{n}=24)$ or reporting they had undergone major abdominal surgery $(\mathrm{n}=8)$ were excluded from analysis, leaving a total sample of 1085 eligible participants with data. 
Table 1 Criteria used to define risk categories in accordance with national CRC screening guidelines.

\begin{tabular}{ll}
\hline $\begin{array}{l}\text { Risk Category* } \\
\text { At or slightly above }\end{array}$ & $\begin{array}{l}\text { • No personal history of bowel cancer. } \\
\text { relative with bowel cancer diagnosed at age } 55 \text { years or older. }\end{array}$ \\
\hline Moderately increased risk & $\begin{array}{l}\text { - One first-degree relative diagnosed before the age of } 55 \text { years (without potentially high-risk features listed below), or } \\
\text { Two first-degree relatives or one first- and one second-degree relative(s) on the same side of the family (without } \\
\text { potentially high-risk features listed below). }\end{array}$ \\
\hline Potentially high risk & $\begin{array}{l}\text { - Three or more first-degree or a combination of first-degree and second-degree relatives on the same side of the family } \\
\text { diagnosed with bowel cancer (suspected HNPCC**), or Two or more first-degree or second-degree relatives on the same } \\
\text { side of the family diagnosed with bowel cancer, including the following risk feature: bowel cancer before the age of } 50 \\
\text { years or at least one-relative with cancer of the endometrium, ovary, stomach, small bowel, renal pelvis, ureter, biliary } \\
\text { tract or brain. }\end{array}$ \\
\hline
\end{tabular}

* Risk features potentially placing persons at possible increased risk, including personal history of adenoma, inflammatory bowel disease or suspected familial adenomatous polyposis (FAP) were not assessed in the survey. ${ }^{*} \mathrm{HNPCC}$ (Hereditary non-polyposis colorectal cancer), also known as Lynch syndrome.

1061 participants provided adequate family history information for the purposes of risk allocation. Sociodemographic characteristics and the proportion of respondents at each level of risk are presented in Table 2.

Table 2 Socio-demographic characteristics of study respondents $(n=1085)$

\begin{tabular}{|c|c|c|}
\hline Characteristic & n & $\%$ \\
\hline \multicolumn{3}{|l|}{ Gender } \\
\hline Male & 508 & 47 \\
\hline Female & 577 & 53 \\
\hline \multicolumn{3}{|l|}{ Age (years) } \\
\hline $56-64$ & 455 & 42 \\
\hline $65-74$ & 382 & 36 \\
\hline $75-88$ & 237 & 22 \\
\hline \multicolumn{3}{|l|}{ Country of Birth } \\
\hline Australia & 885 & 89 \\
\hline Other & 111 & 11 \\
\hline \multicolumn{3}{|l|}{ Marital status } \\
\hline In a relationship & 805 & 77 \\
\hline Not in relationship & 240 & 23 \\
\hline \multicolumn{3}{|l|}{ Risk category } \\
\hline At or slightly above average risk & 979 & 92 \\
\hline Moderately increased risk & 52 & 5 \\
\hline Potentially high risk & 30 & 3 \\
\hline \multicolumn{3}{|l|}{ Annual household income before tax (\$) } \\
\hline$<=39,999$ & 574 & 58 \\
\hline $40,000-69,999$ & 216 & 22 \\
\hline$>=70,000$ & 197 & 20 \\
\hline \multicolumn{3}{|l|}{ Highest Level of Education } \\
\hline Secondary schooling (not-completed) & 229 & 22 \\
\hline Secondary schooling (completed) & 241 & 23 \\
\hline Trade qualification or TAFE: & 264 & 25 \\
\hline University or other tertiary study & 256 & 25 \\
\hline Other or not applicable & 53 & 5 \\
\hline
\end{tabular}

* Percentage of responses (excluding any missing values).

\section{Family history of CRC assessment}

1050 respondents provided information on "ever asked about family history of CRC by a health care provider" (Yes/No). Overall 38.3\% (95\% CI, 35.3 - 41.3) of respondents had ever been asked if they had a family history of CRC by a health care provider. Risk category specific rates were as follows: "at or slightly above average risk" (36.6\%, 33.6 - 39.7), "moderately increased risk" (54.9\%, 40.3 - 68.9) and "potentially high risk" (65.6\%, 45.7 82.1). Table 3 presents the results of the multiple logistic regression analysis. Persons with a higher education (university or other tertiary study), ever receiving screening advice from a health care provider and with lower physical component summary (PCS) score on the SF-36 were significantly more likely to have ever had been asked about their family history of CRC by a health care provider.

\section{Health care providers' practice relating to notification of "increased risk" to persons at elevated levels of risk ("moderately increased/potentially high risk")}

Of the 82 respondents classified at "moderately increased risk" or "potentially high risk", 78 persons provided information relating to "discussion of family history of CRC with doctor". 42.3\% (95\% CI 31.2 - 54.0) of such persons had never been asked by a health care provider about their family history of CRC. 51.3\% (39.7 62.8) had been both asked about their family history of CRC and notified of possible "increased risk". A further 6.4\% (2.1-14.3) had been asked about their family history of CRC but were not informed of any possible "increased risk".

\section{Health care providers' practice relating to CRC screening recommendation}

Across the entire cohort 978 respondents provided information on CRC screening advice. Overall, 31.1\% (95\% CI 28.2 - 34.1) of respondents had ever received screening advice from a health care provider. Risk-specific rates of receiving screening advice for persons were: 
Table 3 Multiple logistic regression analysis $(n=870$ )* of factors associated with ever asked about family history of CRC by a health care provider

\begin{tabular}{|c|c|c|c|}
\hline & Asked by health care provider $\mathrm{n}(\%)$ & OR $(95 \% \mathrm{Cl})$ & $p$-value \\
\hline \multicolumn{4}{|l|}{ Education } \\
\hline Secondary schooling (not-completed) & $61(34)$ & 1 & \\
\hline Secondary schooling (completed) & $67(33)$ & $.99(.61,1.62)$ & .974 \\
\hline Trade qualification or TAFE: & $83(38)$ & $1.24(.77,2.00)$ & .373 \\
\hline University or other tertiary study & $108(48)$ & $2.14(1.34,3.45)$ & .002 \\
\hline Other or not applicable & $19(44)$ & $1.89(.88,4.05)$ & .102 \\
\hline \multicolumn{4}{|l|}{ Ever received screening advice from } \\
\hline \multicolumn{4}{|l|}{ doctor } \\
\hline Yes & $206(73)$ & $10.11(7.24,14.12)$ & .000 \\
\hline No & $132(22)$ & 1 & \\
\hline SF-36 (PCS) & - & $.98(.96, .99)$ & .012 \\
\hline
\end{tabular}

* Respondents excluded from model due to missing values $(n=191)$

$27.7 \%(24.8$ - 30.7) for those "at or slightly above average risk", $67.3 \%(24.8-30.7)$ for those at "moderately increased risk" and $80.8 \%(60.6-93.4)$ for those at "potentially high risk". Multiple logistic regression analysis (See Table 4) found that persons: at elevated level of risk ("moderately increased/potentially high risk") and who had ever discussed family history of CRC with doctor irrespective of whether informed of "increased risk" were significantly more likely to ever had received screening advice from a health care provider.

Risk notification and CRC screening recommendation for persons at elevated levels of risk ("moderately increased/ potentially high risk")

Of the 82 respondents at either 'moderately increased risk' or 'potentially high risk' 72 persons provided information on both 'discussion of family history of CRC with doctor' and 'ever received CRC screening advice'. For respondents at each respective level of risk; 95\% (38/40) of persons notified of their 'increased risk' of CRC had ever received screening advice compared to $37 \%(10 / 27)$ of respondents who had never discussed their family history of CRC with a doctor. Eighty per cent (4/5) of persons who had discussed their family history of CRC with a doctor but were not informed of their 'increased risk' had ever received CRC screening advice.

\section{Discussion}

Study findings indicate that opportunities for earlier detection of CRC are being missed, with $38 \%$ of all respondents ever asked about their family history of CRC by a health care provider. Of concern is that close to half of persons at "moderately increased/potentially high risk" had not been notified of their "increased risk" by a health care provider. Overall, the rate of screening advice was low with approximately one-third of respondents irrespective of risk category ever receiving CRC screening advice from a health care provider.

Risk-based colorectal cancer screening

Before further consideration of study findings, the importance of "risk-based" screening and some

Table 4 Multiple logistic regression analysis $(n=956) *$ of factors associated with ever receiving CRC screening advice from a health care provider

\begin{tabular}{lll}
\hline & $\begin{array}{l}\text { Received screening advice } \\
\mathbf{n}(\%)\end{array}$ & OR (95\%Cl)* \\
\hline Risk Category & $239(27)$ & 1 \\
\hline At or slightly above average risk & $32(68)$ & $4.45(2.07,9.55)$ \\
\hline Moderately increased risk & $20(80)$ & $6.92(2.20,21.71)$ \\
\hline Potentially high risk & $81(13)$ & .000 \\
\hline Discussion of family history of CRC with doctor & $152(76)$ & $17.96(11.97,26.95)$ \\
\hline Discussed/informed of 'increased' 'risk' & $58(38)$ & $4.12(2.73,6.20)$ \\
\hline Discussed/not informed of increased 'risk' & .000 \\
\hline
\end{tabular}

* Respondents excluded from model due to missing values $(n=105)$ 
constraints of population-level CRC screening must be addressed. Population-level screening has demonstrated effectiveness with RCTs indicating a CRC mortality reduction between 15 to $33 \%$ [3,4,8-10], with a slightly higher benefit secured from sigmoidoscopic screening [11]. At present, there is still no RCT evidence for colonoscopy screening. While population-level screening indicates efficacy for the "average risk" population it does not cater for the tailored screening requirements of higher risk groups. Risk-based screening, as adopted in the Australian clinical practice guidelines [6], is an attempt to address the critical relationship between strong family history of CRC and the increased likelihood of developing the disease. This risk-based approach to screening, also acknowledges the problem of over screening, which can be harmful, costly and unnecessary. While it is pertinent all patients receive CRC screening advice from their healthcare provider, it is critical that family history of cancer discussions guide risk-appropriate CRC screening provision to patients. Correct risk assignment and clinical management is of critical importance for patients with family histories suggestive of hereditary cancer syndromes.

\section{Family history assessment in the primary care setting}

Family history assessment is important for identification of those who may benefit from tailored screening or referral to genetic services. This study suggests that the important first-step in identification of risk - discussion of family history of CRC- often does not occur. Such findings are consistent with previous data identifying poor documentation of family history information in the family practice setting $[18,23,26,28,42]$. It must be acknowledged that family history assessment and notification of risk does not ensure continued adherence to screening recommendations [43]. Nonetheless, risk communication is an essential prerequisite to patients' understanding of their risk. Current study findings suggest the need for strategies that help to improve the assessment of family history of CRC and the identification of potential familial risk in the primary care-setting

\section{Improving family history assessment and referral}

Health care providers report the need for clear guidance on the risk stratification and referral process of patients $[44,45]$. Further refinement of user-friendly guidelines that help to facilitate identification and referral of increased-risk patients is an important yet necessary step forward as suggested by other researchers $[18,42,44,46]$. The cumbersome and time-consuming nature of family history assessment has been a barrier to accurate assessment of familial risk [46-48], which may in part be overcome by the advent of computerised Cancer Risk Assessment Tools (CRATs) which have helped to standardise and simplify family history assessment $[49,50]$. Interventions using this technology designed to efficiently assess and automate risk stratification are likely to increase the utility of family history assessment in the primary health care setting [51]. Recent cluster randomised controlled trials have demonstrated this tool's effectiveness in the management of familial breast and CRC including a trial which compared a computer decision support aid versus best evidence practice (education and guideline dissemination) $[19,52]$.

\section{Improving the CRC screening message to the at-risk population}

Current findings indicate the need for practice-based strategies that systematically prompt health care providers to encourage CRC screening among at-risk patients, especially given patients are often reluctant to initiate discussions [53]. Little data exists on how often CRC screening is included in office reminder systems and the reasons for under utilisation in the primary health care setting [53]. Although meta-analyses have demonstrated that minimal prompts to patients and providers are effective in enhancing CRC screening with FOBT [54], research suggests very limited use of such reminder systems for CRC screening $[54,55]$. Intuitively maximising the wider adoption of simple systematic practice-based interventions that include prompts to health care providers for CRC screening may assist in elevating CRC screening rates across the at-risk population.

\section{Study limitations}

The findings should be interpreted in light of some methodological limitations. Health care providers' practices relating to preventive measures in this study were based on self-report with associated potential for recall bias. Selfreported family history of CRC was not validated against objective sources, a limitation however that is consistent with other published studies that have used patient record audit $[18,23,28]$. For a small minority of respondents at "moderately increased/potentially high risk", the level of risk may have been overestimated. For respondents indicating that both a first- and second-degree relative were diagnosed with CRC, an assumption was made that both relatives were diagnosed on the same side of the family. Participants' report of health care providers' assessment of patient family history of CRC may have been underestimated due to several factors including recall bias. It is possible that health care providers may have asked a broader question about family history of cancer or respondents could have instigated family history discussions without health care providers' initiation. However, the literature suggests such patient initiation is rare[53]. Alternatively, 
health care providers may have been aware of a persons' familial risk from information obtained previously from other relatives in the family with notification of "increased risk" given on this basis. Further, it is important to consider that for some persons their risk-status may have changed over-time (since first discussion of family history with a doctor). That is, some persons asked about their family history of CRC (years prior to survey completion) may have had no family history of CRC at this time and were correctly notified of no "increased risk", yet at a later stage, following a relative's diagnosis of CRC were notified by a doctor of their "increased risk". While this may have occurred in a small number of persons, the literature suggests that periodic updating of family history of CRC information is seldom conducted in the primary-care setting $[22,26,56]$. Subsequently, it is highly possible that for the most part, persons with a changed family history of CRC overtime would not have been notified of their changed risk status. Finally, some participants (recently turning 55 or 65 years of age) may have had recent contact with the National Bowel Cancer Screening Program prior to survey completion. As part of this program, an FOBT screening invitation and information on familial risk and CRC screening is provided, which may have increased $\mathrm{CRC}$ awareness in this particular respondent group.

\section{Conclusions}

The current study's evaluation of patient self-report suggests that family history of CRC discussions with a health care provider had occurred in a minority of cases. Consequently, many families at the greatest risk of developing CRC may have missed a vital opportunity to gain benefits from increased risk notification, riskappropriate screening and adequate referral to genetic consultation. Greater emphasis on the refinement and development of user-friendly referral guidelines, the wider incorporation of office-based reminder and computer-based technology to facilitate risk assessment and $\mathrm{CRC}$ screening recommendation is required.

\section{Funding}

The project was funded by the Lion's Club of Adamstown in conjunction with the Hunter Medical Research Institute.

\section{Additional material}

Additional file 1: Appendix A. Items and response options (verbatim) used to assess respondents family history. Appendix B. Simple logistic regression analyses of factors associated with ever asked about family history of CRC by a healthcare provider and ever receiving CRC screening advice.

\section{Acknowledgements}

The research on which this paper is based was conducted as part of the Hunter Community Study, The University of Newcastle. We are grateful to The University of Newcastle, the Hunter Medical Research Institute \& Lions Club of Adamstown for funding and to the men and women of the Hunter region who provided the information recorded. We thank Roseanne Peel for her contribution to the development of the studied cohort; Stephen Hancock for design of the current study's database; Tracey Watt for her assistance with data entry and the mail out/reminder call process; and Daniel Barker and Michael Fitzgerald for their statistical support. Recognition and thanks to Australian Rotary Health Research Fund and the Rotary District 9650 Bowelscan Committee for their funding of PhD scholar - RJC.

\section{Author details}

${ }^{1}$ The Priority Research Centre for Health Behaviour, School of Medicine and Public Health, Faculty of Health, The University of Newcastle, Newcastle, Australia. ${ }^{2}$ Department of Colorectal Medicine and Genetics, The Royal Melbourne Hospital, Newcastle, Australia. ${ }^{3}$ The Centre for Clinical Epidemiology and Biostatistics, Faculty of Health, The University of Newcastle, Newcastle, Australia. ${ }^{4}$ Hunter Medical Research Institute, Newcastle, Australia.

\section{Authors' contributions}

RJC, CLP, RSF were responsible for study design, data collection, analysis and drafting. All authors contributed to the interpretation of results and writing of this manuscript.

\section{Competing interests}

The authors declare that they have no competing interests.

Received: 28 November 2011 Accepted: 14 March 2012

Published: 14 March 2012

\section{References}

1. World Health Organisation: International Agency for Research on Cancer. GLOBOCAN. Cancer incidence and mortality worldwide in 2008.[http:// globocan.iarc.fr/factsheets/cancers/colorectal.asp].

2. National Cancer Institute: Surveillance Epidemiology and End Results. SEER Stats Fact Sheets. Colon and rectum cancer survival and stage. [http://seer.cancer.gov/statfacts/html/colorect.html].

3. Hardcastle JD, Chamberlain JO, Robinson MHE, Moss SM, Amar SS, Balfour TW, James PD, Mangham CM: Randomised controlled trial of faecal-occult blood screening for colorectal cancer. Lancet 1996, 348:1472-1477.

4. Mandel JS, Church TR, Bond JH, Ederer F, Geisser MS, Mongin SJ, Snover DC, Schuman LM: The effect of fecal occult-blood screening on the incidence of colorectal cancer. N Engl J Med 2000, 343:1603-1607.

5. Winawer SJ, Zauber AG, Ho MN, O'Brien MJ, Gottlieb LS, Sternberg SS, Waye JD, Schapiro M, Bond JH, Panish JF, Ackroyd F, Shike M, Kurtz RC, Hornsby-Lewis L, Gerdes H, Stewart ET: National Polyp Study Workgroup. Prevention of colorectal cancer by colonoscopic polypectomy. N Engl J Med 1993, 329:1977-1981.

6. Australian Cancer Network Colorectal Cancer Guidelines Revision Committee: Clinical practice guidelines for the prevention, early detection and management of colorectal cancer.[http://www.nhmrc.gov. au/_files_nhmrc/publications/attachments/cp106_0.pdf].

7. Levin B, Lieberman DA, McFarland B, Smith RA, Brooks D, Andrews KS, Dash C, Ciardiello FM, Glick S, Levin TR, Pickhardt P, Rex DK, Thorson A, Winawer SJ: American Cancer Society Colorectal Cancer Advisory Group; US Multi-Society Task Force; American College of Radiology Colon Cancer Committee. Screening and surveillance for the early detection of colorectal cancer and adenomatous polyps, 2008: a joint guideline from the American Cancer Society, the US Multi-Society Task Force on Colorectal Cancer, and the American College of Radiology. CA Clin J Clin 2008, 58:130-160.

8. Hunter W, Farmer A, Mant D, Verne J, Northover J, Fitzpatrick R: The effect of self-administered faecal occult blood tests on compliance with screening for colorectal cancer: Results of a survey of those invited. Fam pract 1991, 8:367-372. 
9. Kronborg O, Fenger C, Olsen J, Jorgensen OD, Sondergaard O: Randomised study of screening for colorectal cancer with faecal occult blood test. Lancet 1996, 348:1467-1471.

10. Mandel JS, Bond JH, Church TR, Snover DC, Bradley GM, Ederer F: Reducing mortality from colorectal cancer by screening for fecal occult blood. Minnesota colon cancer control study. N Engl J Med 1993, 328:1365-1371.

11. Atkin WS, Edwards R, Krajl-Hans I, Wooldrage K, Hart AR, Northover J, Hart AR, Northover JMA, Parkin MD, Wardle J, Duffy SW, Cuzick J: Onceonly flexible sigmoidoscopy screening in prevention of colorectal cancer: a multicentre randomised controlled trial. Lancet 2010, 375:1624-1633.

12. Crespi M, Stigliano V, Assisi D: Current trends and secondary prevention of colorectal cancer. Hepatogastroenterology 2001, 48:1635-1640.

13. Madlensky L, Esplen MJ, Gallinger S, McLaughlin JR, Goel V: Relatives of colorectal cancer patients. Factors associated with screening behavior. Am J Prev Med 2003, 25:187-194.

14. Australian Cancer Network and Commonwealth Department of Health and Ageing: Familial aspects of bowel cancer: A guide for health professionals.[http://www.cancerscreening.gov.au/internet/screening/ publishing.nsf/content/1F35A75DC194E59CCA2574EB007F7532/\$File/familialguide.pdf].

15. Butterworth AS, Higgins JP, Pharoah P: Relative and absolute risk of colorectal cancer for individuals with a family history: A meta-analysis. Eur J Cancer 2006, 42:216-227.

16. Johns LE, Houlston RS: A systematic review and meta-analysis of familial cancer risk. Am J Gastroenterol 2001, 96:2992-3003.

17. St John DJB, McDermott FT, Hopper JL, Debney EA, Johnson WR, Hughes ESR: Cancer risk in relatives of patients with common colorectal cancer. Ann intern Med 1993, 118:785-790

18. Tyler CV, Synder CW: Cancer risk assessment: Examining the family physician's role. J Am Board Fam Med 2006, 19:468-477.

19. O'Neill SM, Rubenstein WS, Wang C, Yoon PW, Acheson LS, Rothrock N, Starzyk EJ, Beaumont JL, Galliher JM, Ruffin MT: Family Healthware Impact Trial Group. Familial risk for common diseases in primary care: the Family Healthware Impact Trial. Am J Prev Med 2009, 36:506-514.

20. Guttmacher AE, Collins FS, Carmona RH: The family history - more important than ever. N Engl J Med 2004, 351:2333-2336.

21. Rich EC, Burke W, Heaton CJ, Haga S, Pinksy L, Short MP, Asheson L: Reconsidering the family history in primary care. J Gen Intern Med 2004, 19:273-280.

22. Medalie JH, Zyanski SJ, Langa D, Stange KC: The family in family practice: is it reality? J Fam Pract 1998, 46:390-396.

23. Sifri RD, Wender R, Paynter N: Cancer risk asssessment from family history: Gaps in primary care practice. J Fam Pract 2002, 51:856.

24. Smith RA, von Eschenbach $A C$, Wender RC, Levin $B$, Byers $T$, Rothenberger D, Brooks D, Creasman W, Cohen C, Runowicz C, Saslow D, Cokkinides V, Eyre H: ACS Prostate Cancer Advisory Committee, ACS Colorectal Cancer Advisory Committee, ACS Endometrial Cancer Advisory Committee. American Cancer Society guidelines for the early detection of cancer: update of early detection guidelines for prostate, colorectal and endometrial cancers. Also: update 2001 - testing for early lung cancer detection. CA Cancer J Clin 2001, 51:77-80.

25. Summerton N, Garrood PV: The family history in family practice: a questionnaire study. Fam Pract 1997, 14:285-288.

26. Acheson LS, Wiesner GL, Zyzanski SJ, Goodwin MA, Stange KC: Familyhistory taking in community family-practice: Implications for genetic screening. Genet Med 2000, 2:180-185.

27. Grover S, Stoffel EM, Bussone L, Tschoegl E, Syndgal S: Physician assessment of family cancer history and referral for genetic evaluation in colorectal cancer patients. Clin Gastroenterol Hepatol 2004, 2:813-819.

28. Murff HJ, Byrne D, Syngal S: Cancer risk assessment. Quality and impact of the family history interview. Am J Prev Med 2004, 27:239-245.

29. Cole SR, Young GP, Byrne D, Guy JR, Morcom J: Participation in screening for colorectal cancer based on a faecal occult blood test is improved by endorsement by the primary care practitioner. J Med Screen 2002, 9:147-152.

30. Sung JJY, Choi SYP, Chan FKL, Ching JYL, Lau JTF, Griffiths S: Obstacles to colorectal cancer screening in Chinese: A study based on the health belief model. Am J Gastroenterol 2008, 103:974-981.

31. Lewis SF, Jensen NM: Screening sigmoidoscopy: factors associated with utilization. J Gen Intern Med 1996, 11:542-544.
32. Shokar NK, Carlson CA, Shokar GS: Physician colorectal cancer screening recomendations: an examination based on informed decision making. $J$ Cancer Educ 2006, 21:84-88.

33. Brawarsky P, Brooks DR, Mucci LA, Wood PA: Effect of physician recommendation and patient adherence on rates of colorectal cancer testing. Cancer Detect Prev 2004, 28:260-268.

34. Guerra CE, Schwartz JS, Armstrong K, Brown JS, Halbert CH, Shea JA: Barriers of and facilitators to physician recommendation of colorectal cancer screening. J Gen Intern Med 2007, 22:1681-1688.

35. Klablunde CN, Vernon SW, Nadel MR, Breen N, Seef LC, Brown ML: Barriers to colorectal cancer screening: A comparison of reports from primary care physicians and average-risk adults. Medical Care 2005, 43:939-944.

36. Klabunde CN, Frame PS, Meadow A, Jones E, Nadel M, Vernon SW: A national survey of primary care physicians' colorectal cancer screening recommendations and practices. Prev Med 2003, 36:352-362.

37. Koo JH, Arasaratnam MM, Redmond DM, Connor SJ, Sung JJY, Leong RWL: Knowledge, perception and practices of colorectal cancer screening in an ethnically diverse population. Cancer Epidemiol 2010, 34:604-610.

38. McEvoy M, Smith W, D'Este C, Duke J, Peel R, Schofield P, Scott R, Byles J, Henry D, Ewald B, Hancock S, Smith D, Attia J: Cohort profile: The Hunter Community Study. Int J Epidemiol 2010, 39:1452-1563.

39. Ware JE, The SCD, MOS: 36 -item short form health survey. Conceptual framework and item selection. Med Care 1992, 30:473-483.

40. Kessler RC, Barker PR, Colpe LJ, Epstein JF, Gfroerer JC, Hiripi E, Normand SL, Manderscheid RW, Walters EE, Zaslavsky AM: Screening for serious mental illness in the general population. Arch Gen Psychiatry 2003, 60:184-189.

41. Ware JE: SF-36 Health Survey Update.[http://www.sf-36.org/tools/sf36 shtml].

42. Flynn BS, Wood ME, Ashikaga T, Stockdale A, Dana GS, Naud S: Primary care physicians' use of family history for cancer risk assessment. $B M C$ Family Practice 2010, 11:45.

43. Schroy PC, Barrison AF, Ling BS, Wilson S, Geller AC: Family history and colorectal cancer screening: A survey of physician knowledge and practice patterns. Am J Gastroenterol 2002, 97:1031-1036.

44. Fry A, Campbell H, Gudmundsdottir H, Rush R, Porteous M, Gorman D, Cull A: GP's view on their role in cancer genetics services and current practice. Fam Pract 1999, 16:468-474.

45. Wood ME, Stockdale A, Flynn BS: Interviews with primary care physicians regarding taking and interpreting the cancer family history. Fam Pract 2008, 25:334-340.

46. Suther S, Goodson P: Barriers to the provision of genetic services by primary care physicians: a systematic review of the literature. Genet Med 2003, 5:70-76.

47. Burke W: Taking family history seriously. Ann intern Med 2005, 143:388-389.

48. Yarnall KS, Pollak Kl, Ostbye T, Krause KM, Michener JL: Primary care is there enough time for prevention. Am J Public Health 2003, 93:635-641.

49. Acheson LS, Zyzanski SJ, Stange KC, Deptowicz A, Wiesner GL: Validation of a self-administered, computerized tool for collecting and displaying the family history of cancer. J Clin Oncol 2006, 24:5395-5402.

50. Westman J, Hampel H, Bradley T: Efficacy of a touchscreen computer based family cancer history questionnaire and subsequent cancer risk assessment. J Med Genet 2000, 37:354-360.

51. Qureshi N, Wilson B, Santaguida P, Carroll J, Allanson J, Ruiz Culebro C, Brouwers M, Raina P: Collection and use of family history in primary care. [http://www.ahrq.gov/downloads/pub/evidence/pdf/famhistory/famhist.pdf].

52. Emery J, Morris H, Goodchild R, Fansshawe T, Prevost AT, Bobrow M, Kinmoth AL: The GRAIDS Trial: a cluster randomised controlled trial of computer decision support for the management of familial cancer risk in primary care. Br J Cancer 2007, 97:486-493.

53. Ellerbeck EF, Engelman KK, Gladden J, Mosier MC, Raju GS, Ahluwalia JS: Direct observation of counselling on colorectal cancer in rural primary care practices. J Gen intern Med 2001, 16:697-700.

54. ME H, Maglione MA, Roth EA, Grimshaw JM, Mittman BS, Rubenstein LV, Rubenstein LZ, Shekelle PG, Stone EG, Morton SC: Interventions that increase use of adult immunization and cancer screening services: a meta-analysis. Ann intern Med 2002, 136:641-645.

55. Klabunde CN, Riley GF, Mandelson MT, Frame PS, Brown ML: Health plan policies and programs for colorectal cancer screening: a national profile. Am J Manag Care 2004, 10:273-279. 
56. Acton RT, Burst NM, Casebeer L, Ferguson SM, Greene P, Laird BL, Leviton L: Knowledge, attitudes, and behaviors of Alabama's primary care physicians regarding cancer genetics. Acad Med 2000, 75:850-852.

\section{Pre-publication history}

The pre-publication history for this paper can be accessed here: http://www.biomedcentral.com/1471-2296/13/17/prepub

doi:10.1186/1471-2296-13-17

Cite this article as: Courtney et al:: Colorectal cancer risk assessment and screening recommendation: a community survey of healthcare providers' practice from a patient perspective. BMC Family Practice 2012 13:17.

Submit your next manuscript to BioMed Central and take full advantage of:

- Convenient online submission

- Thorough peer review

- No space constraints or color figure charges

- Immediate publication on acceptance

- Inclusion in PubMed, CAS, Scopus and Google Scholar

- Research which is freely available for redistribution

Submit your manuscript at www.biomedcentral.com/submit 